\title{
APROXIMACIONES A LA COMPRENSIÓN DE LA (hk3) Y SUS POSIBLES VÍNCULOS CON LA FILOSOFÍA
}

Jorge Ordóñez Burgos ${ }^{1}$

\section{Resumen}

El pensamiento de los pueblos de la Antigüedad se compuso de lenguajes, sistemas de valores y planteamientos que escapan no sólo a los convencionalismos lingüísticos actuales, también resultan ajenos a las categorías propias de la filosofía, la religión y la mitología misma. Un caso revelador es la (hk3) egipcia, traducida a lenguas contemporáneas como magia, magic, Zauber o Magie; en dicho traslado, se le adhiere una serie de connotaciones propias de la mentalidad judeocristiana y evolucionista. Una magia sin más, producto del hombre crédulo, perezoso de mente y supersticioso. Sin embargo, tal reducción no se preocupa en estudiar aspectos de gran trascendencia como el proceso de transmisión que la palabra sufrió al cabo de los siglos, omitiendo el papel que jugó la magia persa dentro de la reflexión de filósofos, historiadores y poetas de la Hélade. La ( $h k 3)$ fue una manera de concebir el universo que no puede reducirse sólo a creencias pseudoreligiosas, fue una sofisticada estructura para entender las cosas que, sencillamente, desconocemos. El presente artículo es una invitación a revisar los productos culturales de siglos lejanos, sin perder de vista que la incomprensión no se da exclusivamente con lo distante, sino en las entrañas mismas de nuestro tiempo.

\section{Palabras clave}

Filosofia antigua; pensamiento egipcio; magia.

\footnotetext{
${ }^{1}$ Professor Doctor, Universidad Autónoma de Ciudad Juárez - Ciudad Juárez, México. email: vonschlegel@gmail.com
} 


\section{Resumo}

O pensamento dos povos da Antiguidade é composto de linguagens, sistemas de valores e proposições que escapam não só aos convencionalismos linguísticos atuais, mas também se distanciam das categorias próprias da filosofia, da religião e até mesmo da mitologia. Um caso ilustrativo é a (VkA) egípcia, cuja tradução nas línguas contemporâneas é magia, magic, Zauber e Magie; nessa tradução, vincula-se uma série de conotações próprias da mentalidade judaico-cristã e evolucionista. Uma simples magia, fruto do homem crédulo, supersticioso e detentor de uma mente preguiçosa. Tal simplificação, entretanto, não se preocupa em estudar aspectos de grande relevância como o processo de transmissão que a palavra sofreu ao longo dos séculos, omitindo o papel desempenhado pela magia persa no interior da reflexão de filósofos, historiadores e poetas da Hélade. A (VkA)foi uma forma de conceber o universo que não pode se limitar somente a crenças pseudo-religiosas; foi uma sofisticada estrutura para entender as coisas que, simplesmente, não conhecemos. Este artigo é um convite a uma revisão dos produtos culturais de séculos distantes, sem perder de vista que a incompreensão não se localiza exclusivamente nesse distante, mas nas próprias entranhas do nosso tempo.

\section{Palavras-chave}

Filosofia antiga; pensamento egípcio; magia. 


\section{La traducción cultural}

El ser humano es inquieto, posee una curiosidad expansiva cuyos límites se redefinen constantemente. Es un animal que gusta de buscar aquí y allá, en sí mismo y en los demás; especula sobre el futuro, revisa el presente desde diversos ángulos y escarba en el pasado con vigor casi infatigable. Hace falta mucho más que entusiasmo para sostener tan extenuante vocación. Salir al mundo con actitud de descubridor, exige saber qué se está buscando -tanto al internarse en las profundidades de la naturaleza como en la complejidad de las civilizaciones-. Es en este segundo contexto donde quiero poner especial atención. Para el presente estudio, será observada una práctica muy arraigada en el antiguo Egipto, la ( $h k 3)$, llevada a idiomas contemporáneos como "magia". Desde la época de los antiguos griegos, han corrido ríos de tinta para intentar captar su significado más profundo. En ciertos momentos se le abordó con admiración, quizá hasta con la devoción que se trata a la Verdad revelada. En otros, con desprecio y entendiéndola llanamente como superstición y expresión máxima de irracionalidad, perteneciente a un estamento evolutivo inferior a otros donde han campeado la ciencia y la "razón". A partir de las condiciones descritas, surgen inquietudes sobre el tratamiento que reciben ésta y otras manifestaciones culturales. ¿Con qué herramientas conceptuales nos disponemos a revisar una actividad tan importante para los egipcios?, ¿qué se busca cuando se le ausculta?, ¿se pretende conocer el pasado o justificar la forma de proceder en el presente? Al voltear la mirada a la Antigüedad, ¿se dispone de los medios para entender las cosas en su nicho humano original o se les juzga con cierto aire de superioridad?

En nuestro artículo, usaremos la expresión traducción cultural para referir el proceso a través del cual un lector, valiéndose del marco referencial propio, establece vínculos entre prácticas más o menos equivalentes desarrolladas por civilizaciones diferentes. Por ejemplo, algunos procesos curativos seguidos por pueblos indígenas son nombrados por nosotros como "curación popular", "medicina alternativa" o "tradicional". Al llamarlas así se deja claro que sus tratamientos no están plenamente apegados a las ciencias y los métodos racionales aprobados por nosotros; además, se puede ver que nuestras categorías no coinciden con las suyas, siendo insuficientes para captar su mentalidad y propósitos. Podría pensarse que la soberbia con que se denigra lo irracional o pseudocientífico es un signo de superioridad y sólo señala las carencias de lo ajeno, sin embargo, exhibe también los vacíos de nuestro marco base. Todo depende del ángulo desde el que se vean las cosas. Sea lo que sea aquello que los otros hacen, no alcanzamos a asimilarlo 
del todo, siendo nuestra racionalidad excesiva un impedimento más que una ayuda. La traducción es una versión de las cosas que nunca es perfecta y certera, empero, no contamos con otro recurso para tener cierta cercanía con lo otro.

En medio de la disparidad, se hace necesario construir puentes para saltar obstáculos. El puente es un camino que se erige sobre acantilados, ríos o vados, dejando geografía debajo de sí. Salva la caminata entre lajas filosas que lastiman el pie del andariego. Aguas turbias y profundas son vistas desde alturas altaneras, andar sobre ellas proporciona un sentimiento de superioridad y seguridad, a veces ilusorio. Se concreta el tránsito de ida, quizá el de vuelta, pero, es mucho lo que se pasa por alto. Al completar la primera parte del recorrido, se consigue llegar a un destino que podría ser hasta ininteligible. Si existiera una máquina del tiempo para transportarse a un ágora griega o a un templo egipcio, posiblemente el choque cultural sería tan fuerte que se llegaría a la conclusión de estar frente a un espejismo o que la realidad se equivoca. Egipto y la Hélade en colores, aromas y sonidos vivos serían discordantes con las reconstrucciones hechas a partir de tratados antiguos tocados por muchas manos, por vasijas vacías exhibidas en vitrinas y pálidos templos a medio derruir. Aun contando con los medios para observar en primera fila la dinámica de un pasado tan distante, sería imposible comprender a plenitud el palpitar de la vida de los antiguos. Se nos exige desarrollar categorías-puente para conectarnos de alguna manera con ellos, sin embargo, a pesar de las facilidades conseguidas, hay aspectos que pasan, por decirlo en una palabra, desapercibidos. Las innumerables limitantes que tenemos para acercarnos a la Antigüedad no quedarían zanjadas con abundante evidencia material y empírica, la comprensión de los antiguos tiene mucho que ver con la actitud seguida para leerlos en su hábitat.

La noción de tiempo que los antiguos tenían hace que las diferencias con nosotros se agudicen. Ciudades con escasa densidad poblacional comparada con la actual- albergaban comunidades concentradas en actividades diarias distintas a las nuestras. El solo hecho de desplazarse de un sitio a otro dentro de la misma ciudad era un proceso simple, no sucedía lo mismo con los viajes a otra población o país; empresa en la que no pocos dejaron la vida cuando se enfrentaron a innumerables dificultades como epidemias, inclemencias climáticas, o el asalto de piratas y salteadores. El desplazamiento redundaba en la noción cotidiana y teórica de espacio y tiempo. Para nosotros es difícil dejar de ver con naturalidad la posibilidad de hacer viajes transcontinentales en unas cuantas horas, proeza divina para 
los arcaicos. En este contexto, diversas prácticas culturales como el comercio, la religión, la guerra, la alimentación o el ahorro, adquirían otras notas y sentidos. La noción de espacio, sin mayores pretensiones y elucubraciones filosóficas era entonces, como es hoy, marco y ancla donde la cultura florece. La irrupción en la Antigüedad, un medio tan extraño al propio, se completa a partir de la omisión de detalles sencillos y comunes que componen la cotidianidad. Al buscar otros aspectos más sofisticados, e. gr. los grandes ideales, abstracciones o los desarrollos tecnológicos, se dejan de lado los elementos "intrascendentes" que determinan ideas, creencias y formas de allegarse al mundo, enraizadas en lo inmediato y tangible.

\section{Perfilando la traducción cultural: los bemoles del presente}

Aún la comprensión del mundo contemporáneo ofrece innumerables dificultades. Pongamos por caso el deporte olímpico a nivel mundial. La preparación de atletas para algunas economías africanas no tiene paralelo con la que se sigue en Estados Unidos o China. El significado que el deporte tiene en cada una de estas naciones nos conduce, en los hechos, a escenarios incompatibles entre sí. Sin embargo, cada cuatro años se habla del deporte olímpico como vínculo de unión y buena voluntad. La realidad tangible nos dice que en cada sociedad el papel del atleta y el deporte se modifican dramáticamente. Mientras que en algunas economías son la figura central en la que convergen los más novedosos avances científicos, tecnológicos y educativos (como el sofisticado diseño de ropa deportiva - elaborada con materiales ultraligeros y resultado de investigaciones multimillonarias exportadas a todo el planeta - o la explotación del talento de brillantes ingenieros que se vuelca en construir jabalinas, trineos, balones, remos y flechas). Por el contrario, en los países del tercer mundo es el reflejo de los privilegios de ciertas élites que se benefician con dádivas burdas e insultantes. Regímenes pegados con alfileres envían delegaciones de deportistas sin el nivel suficiente para competir con las grandes luminarias. Parecería que al participar en encuentros mundiales automáticamente se recibe la legitimación de la comunidad internacional. Entonces, ¿qué es el deporte olímpico en nuestro mundo contemporáneo? No es una pregunta que pueda responderse con facilidad, para lograrlo habría que recurrir a un proceso de traducción cultural. Un ejercicio arduo que exige tener gran conocimiento de las circunstancias de los países del orbe.

En procesos más complejos, caracterizados por la interiorización de ideas y creencias, es todavía más difícil unificar criterios. Por ejemplo, la 
convivencia pacífica de diferentes religiones, ondea como estandarte de la tolerancia en nuestros días. Vemos a patriarcas, pastores, rabinos y cardenales juntarse a orar, protagonizando una danza de la humanidad civilizada, sin embargo, cabe preguntarse ¿a quién o a qué le están orando? Este es otro campo en el que la traducción cultural puede brindarnos cierta ayuda. Cuando se decreta que existe respeto para todas las creencias religiosas de los ciudadanos de un país, es sencillo imaginar en teoría la imposición de dignidad a las creencias, ritos e ideas sobre lo sagrado. No obstante, con gran frecuencia se descalifican prácticas ubicándolas en el terreno de lo "primitivo" o "popular". En el mejor de los casos, dicha etiqueta significa que quienes abrazan tal o cual esquema de creencias son ignorantes y están al margen de una teología racional bien elaborada. Es decir, de un aparato fundante que articule conceptualmente una doctrina, una liturgia, o una soteriología en particular. Por ello, procesiones, adoración de santos e imágenes -no autorizadas por una jerarquía ilustrada, la fe en milagros o la aparición de seres divinos, son sacados de los dominios internos del fiel para ser objeto de auscultación minuciosa. El "experto" determinará si son producto de la superstición o de la religiosidad racional e higiénica. ¿Cuándo es un rito magia y cuándo el ejercicio de una clara revelación divina? ¿Cuándo la teología es tal y cuándo se convierte en fundamentalismo? La tolerancia religiosa, -concesión de la misma dignidad a las creencias y prácticas religiosas ajenas que a las propias-, se desdibuja en el preciso momento en el que se evalúa al ajeno o se intenta atraerlo hacia la propia fe. Es entonces cuando se minimiza lo diferente para sobreponerle algo mejor a criterio del evangelizador-árbitro.

¿Qué es en sentido amplio la religión, la fe?, ¿prácticas cotidianas que involucran todos los aspectos de la vida del individuo? ¿Un arsenal de respuestas a todas las posibles preguntas que puedan salirle al paso al hombre?, ¿una vía sobrenatural para explicar hechos naturales? ¿Es posible opinar sobre creencias personalísimas del hombre llevándolas a un lenguaje antropológico-psicológico que no siempre logra adentrarse en la naturaleza de la fe? En encrucijadas como estas es cuando la traducción cultural puede brindar ciertas aportaciones. Un esfuerzo más o menos completo de comprensión; sin duda, un proceso de interconexión y exploración, pero, también, y en honor a la verdad, una simplificación que siempre deja residuos en el camino. Al incursionar en estudios sobre religiones es importante aceptar que, de origen, es fallida la asimilación plena de la fe del otro, por superficial que ésta sea. Aún la banalidad huye de ser captada plenamente. Quiero enfatizar que acercarse a religiones vivas e incrustadas 
en el mismo ámbito social, significa un reto importante para el investigador. ¿Qué puede esperarse de creencias tan lejanas como las de los egipcios? Hacer historia de las religiones es complicado, de ninguna manera ocioso, pero exige un esfuerzo que resultará incompleto siempre, así son los límites del saber humano. No es exclusivo de este campo, en los estudios culturales existen fronteras infranqueables que deben asumirse más que negarse $o$ minimizarse.

Sucede algo similar con las investigaciones comparativas de filosofía, detectando excesos preocupantes en los últimos cien años; en el pasado y en el presente, en América y Europa, una tradición anula a otra, considerándola fincada en falacias o baladí. Buena parte de la historia de la filosofía del siglo pasado se desarrolló a través de la denigración de unas escuelas a otras. La reflexión se concentraba en elaborar argumentos que pusieran contra la pared al oponente, más que en construir pensamiento original. Hoy en día es complicado hacer coincidir en el mismo planeta y momento a la filosofía geopolítica contemporánea de Estados Unidos y a algunas variantes del neokantianismo europeo actual. La primera, creada por estadistas y politólogos, la segunda erudita y apuntalada por recursos poderosos tomados de la filología, el psicoanálisis, lecturas tardías del marxismo y el neotomismo. Caricaturizando la pluralidad del pensamiento, llamamos a ambas "filosofía" sin precisar que se hace una abstracción o reducción, sin atender las variantes que cualquier práctica humana tiene por naturaleza. La cuestión es más profunda, dado que el significado social y práctico de las reflexiones del norteamericano parten de una base que, si bien comparte algunos elementos de su correlato europeo de los últimos dos siglos, en esencia, renuncia a ceñirse a procedimientos "especulativos estériles", según sus propósitos utilitarios. Es una filosofía cuyos engranes son la ofensiva comercial mundial, el manejo estratégico de medios de comunicación, además de la apertura de nuevos mercados que validarán el ajedrez político jugado de manera correcta. Un filosofar que, sencillamente pasa de los griegos, los medievales y la Escuela de Frankfurt. A su vez, los europeos calificarán de filosofastros a los americanos por no ser partícipes de la filosofía. En este contexto, el estudio de la Antigüedad no es el único medio que ofrece problemas de comprensión cultural. Si a las religiones y a la filosofía del Occidente contemporáneo, es difícil abordárseles sin toparse con problemas de incompatibilidad ise tiene autoridad para juzgar a los antiguos, menospreciando su forma de pensar y creer? Señalo las paradojas para comprender las religiones y la filosofía porque es en ese contexto donde podría encuadrarse a la Es imposible conseguir 
integridad absoluta en los métodos de investigación, quizá la actitud más racional a seguir consistiría en aceptar las propias inconsistencias.

Quisiera proponer algunos principios que podrían servir para tener un acercamiento mínimo con el pensamiento que no es propio.

I) Plantear la idea de "otredad" bajo la convicción que se "dignifica" al otro, es, más bien, adoptar una postura un tanto soberbia. Todo aquello que "no soy yo" existe con independencia de mí -sin importar como yo lo denigre o enaltezca- y ofrecerá cierta resistencia a ser entendido. La primera barrera se da en mí, puesto que en cierta medida, siempre intentaré conectar lo desconocido, lo "no propio" al universo personal. Por mucha objetividad que pretenda conseguirse, las vivencias, creencias, ideas y costumbres del otro se harán accesibles mediante las categorías del que observa. La otredad no sólo se da con el habitante de tierras lejanas, poseedor de reglas de convivencia diferentes a las mías, también con un vecino o miembro de mi familia, quien, a pesar de tener marcos referenciales más o menos cercanos, ha elaborado un universo autónomo distinto al mío. Es decir, tendrá un código de traducción diferente al que yo tengo.

II) Es verdad que al acercarse a otras civilizaciones se hace una valoración de ellas, pero es preciso eliminar calificativos como "libre", "evolucionado", "pagano", "científico", "tecnológico", "popular", "precientífico", "irracional", "mítico", "supersticioso", "democrático" y todos aquellos que tengan una fuerte carga axiológica para nosotros. Adjetivos que comprometan la concepción de los otros, al grado de denigrarlos considerándolos en un estamento inferior al nuestro. Rechazaríamos que unos confucianos echaran por la borda milenios de filosofía occidental porque nuestros pensadores no contemplan el término 善 $(j e n / r e n)^{2}$ como

\footnotetext{
2 Simon Leys en su comentario a las Analectas (4.1) de Confucio señala sobre esta palabra: "...la virtud suprema, a menudo traducida como "bondad", "benevolencia" o "virtud". La persona que la practica es "el hombre bueno", "el hombre virtuoso", "el hombre plenamente humano". Normalmente he traducido este término por "humanidad", pero en ocasiones he utilizado "bondad"... Huelga decir que todas estas traducciones han sido irremediablemente inadecuadas; el peor error sería describir a Confucio con los pálidos colores de una especie de filántropo benigno o de trabajador social bienintencionado. Ninguna otra imagen podría estar más lejos de la realidad histórica. Para Confucio, ren, la plenitud de la humanidad, es verdaderamente un absoluto de inexpresable y cegador esplendor; este absoluto es lo que exige heroicidades a cada persona, pero permanece cercano y a mano en la vida cotidiana; nadie lo posee, pero informa todos nuestros actos aunque nunca puede ser totalmente captado, está constantemente revelándose en sus diversas manifestaciones."( 1998: 203-204). El trabajo de Paul Lüth, Die japanische Philosophie (Tübingen: J.C.B. Mohr, 1944), puede brindarnos más elementos para acercarnos a la problemática de otras filosofías cuyos referentes e intereses no tienen paralelo con las nuestras.
} 
parte sustancial de la ética y la cosmología. ¿Qué nos justifica, entonces, a desacreditar esquemas de pensamiento que no se sujetan a la "razón"? Es imposible deshacerse por entero de prejuicios, prenociones y categorías culturales, empero, ayudaría a evitar el alejamiento abstenerse de usar lo más posible de las etiquetas señaladas. Asumir una actitud de esta naturaleza, podría asfaltar el camino hacia otras culturas.

III) Por estrategia metodológica, se asume que los "demás", entiéndase los antiguos, son muy diferentes a nosotros. Pueden serlo, pero, dentro del proceso de traducción cultural es importante encontrar aspectos que nos sean comunes. La cotidianidad puede ser una fuente significativa de vinculación. Relacionarse con algunos aspectos de la vida diaria de pueblos tan distantes, es un gran esfuerzo para el investigador; la subsistencia, la alimentación, la convivencia o la manera en que la muerte se acepta son áreas en las que pueden encontrarse algunas coincidencias con nosotros. A partir de allí podría empezarse con la traducción cultural. Es inevitable cometer anacronismos, sin embargo, no debe pasarse por alto que lo que se busca es un acercamiento a sociedades que estuvieron vivas en su momento.

IV) En el caso concreto del pensamiento y las diferentes denominaciones que los pueblos le dan (filosofía, sabiduría, reflexión, memoria o iluminación) es necesario comprender que siempre se estará sujeto a un marco regulatorio. Ya sea a una tradición ritual, una religión, el estado, la magia o la oralidad, nótese que echo mano del material conceptual que dispongo para expresarme. Lo cual, no significa que las meditaciones que se hayan conseguido en ámbitos diferentes no puedan brindar una aportación relevante para nuestro filosofar.

V) Es necesario asumir que la filosofía occidental contemporánea también está suscrita a marcos que, dentro de las sociedades vivas resultan ser lo más viable y obvio. Nuestra filosofía es racional, remitiéndonos al complejo y ambiguo universo de la razón occidental. Es científica, democrática, humana, abierta, tolerante... cada adjetivo abre espacios que no son del todo conscientes para nosotros. Espacios que no son unánimemente aceptados hoy por todos los habitantes de este planeta.

VI) Como ejercicio historiográfico, es conveniente imaginar cómo serían estudiadas nuestras civilizaciones en algunos milenios. Quizá, nuestros colegas del futuro -me valgo de la traducción cultural para invocarlos- ni siquiera consideren importante el tema de la tecnología, la ciencia, la democracia o el cristianismo. Posiblemente, nuestras sociedades tendrán 
otros atractivos para ellos, otros, ocultos en lo más profundo de nuestra inmediatez, vedados a nuestros ojos.

VII) En las circunstancias particulares de la Antigüedad, es importante asumir que nos enfrentamos a un mundo en movimiento constante cuya dinámica probablemente no alcanzamos siquiera a dimensionar. Hay tantos pueblos que nos pasan inadvertidos y a otros los conocemos por referencias fugaces, ergo, es irresponsable y arriesgado elaborar juicios categóricos sobre ellos. Por ejemplo, Etruria, enclavada en la Europa "familiar", cercana a romanos y griegos, constituye un duro golpe para nuestra arqueología. Una civilización casi tangible pero distante y enigmática nos recuerda que a Europa antigua la perfilamos en sombras. Se dictamina con rapidez que las sociedades fuera del ámbito grecorromano fueron primitivas y carentes de complejidad. Celtas, jutos, eslavos, íberos, bretones, escitas y germanos son minimizados a aldeas gobernadas por hechiceros. Es incorrecto que milenios sean juzgados bajo los cerrados parámetros de lo que entendemos por "Grecia" y "Roma".

Dicho lo anterior, iniciemos nuestro intento por traducir la idea de

\section{La conformación del término "magia": un problema de traducción cultural}

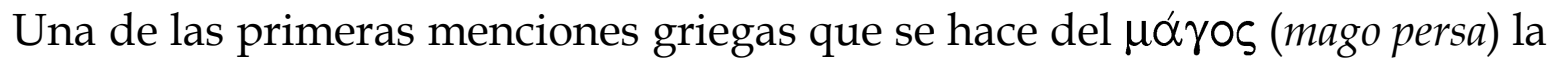
encontramos en la Historia del viejo Heródoto. Aunque su referencia no se reduce a un pasaje único, es en I, 132,2 donde se le define con mayor detalle, a saber, una especie de sacerdote oficiante perteneciente a una de las etnias que componían el imperio persa ${ }^{3}$. En III, 70-79 se describen las intrigas y tensiones políticas que protagonizaron algunos magos, encuadrándolos en las más altas esferas del poder imperial, añadiendo un elemento mundano al religioso para redondear su perfil. Siguiendo la lógica que se aplica con Pitágoras como creador de la palabra filosofía a partir de identificarse a sí mismo como filósofo, la $\mu \alpha \gamma \varepsilon \iota \alpha$ serían las prácticas, creencias e ideas propias

\footnotetext{
${ }^{3}$ Walter Burrkert comenta sobre el término dy[üucc (maguš) dentro del contexto persa: “...el término "mago" está prácticamente ausente en el Avesta [aparece sólo en Yasna 65,7]. Pero una documentación auténtica sobre los magos como funcionarios religiosos existe en las tablillas elamitas de Persépolis de la época de Darío [Koch, 1992: 279 s]... De la zona fronteriza entre helenismo e iranismo, es decir, de la Capadocia, proviene una inscripción bilingüe, greco-aramea,

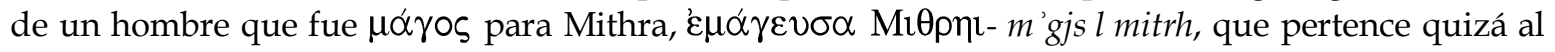
siglo I d.C." (2002: 135). -Para una revisión histórica del término maguš, Cf. el artículo "Magi" de Muhammad A. Dandamayev (2012), disponible en http://www.iranicaonline.org/articles/magi.
} 
de los magos persas 4 . Es importante recordar que la exposición de Heródoto sobre cultos religiosos extranjeros no siempre despeja dudas, por el contrario, deja con la inquietud respecto a si se está ante un ejercicio de pedagogía consistente en helenizar lo foráneo con el objeto de hacerlo más comprensible para el público; si es una reducción de creencias y divinidades que no tienen la estatura de lo griego o, el desarrollo de una traducción cultural en la que muchas cosas se quedan en el camino, pero, no puede concretarse de otra manera más que a través del lenguaje que Heródoto y su gente hablaban ${ }^{5}$. ¿A qué se referiría el de Halicarnaso cuando afirmaba que los magos entonaban una $\theta \varepsilon$ covovín durante los sacrificios (I, 132,2)? ¿En realidad era una pieza que hablaba del origen de los dioses iranios o eran ensalmos, conjuros o tal vez un género que no tiene paralelo dentro de nuestras tradiciones como sucede, por ejemplo, con los "himnos" sumerios? Lo que sí puede concluirse es que Heródoto tenía una buena opinión de los persas y sus instituciones, haciendo eco de la mentalidad de su tiempo. En algunos círculos, el $\mu \alpha ́ \gamma \gamma \varsigma_{\zeta}$ no era un personaje nefasto; el sentido del término cambió, pasando de ser un cuasi gentilicio bárbaro a una manera de referirse a sacerdotes griegos relacionados con los misterios y las iniciaciones. Así lo explica Raquel Martín Hernández (2008: 805), apoyándose en un pasaje del Papiro Derveni (Col. VI) y en un fragmento de Heráclito (Clem. Al. Prot. 2.22.2) ${ }^{6}$ :

...no es necesario pensar que los expertos que realizan dichos ritos sean profesionales venidos de fuera, por mucho que pueda despistar el nombre de origen iranio que se les aplica. Dicho término, creemos, puede ser fácilmente explicado como un tecnicismo religioso, en concreto, un término técnico para denominar a los expertos en rituales de ciertas ceremonias mistéricas, posiblemente relacionadas con el dionisismo...

\footnotetext{
${ }^{4}$ De acuerdo con SUDA x, 9, un artículo dedicado a Janto, se dice que él escribió una historia de Lidia en 4 libros $(\Lambda v \delta i \alpha \kappa \alpha)$. Guido Schepens, en su comentario al FGrH 765, menciona la posibilidad que el catálogo de obras de Janto se compusiera, además del texto citado, de un estudio

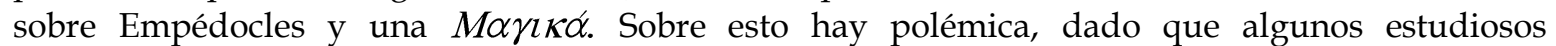
especulan que la $M \alpha \gamma \iota \kappa \alpha ́$. era unos de los libros de la historia de los lidios.Cf. Jacoby (1998: 34, N. 16)

${ }^{5}$ Considero que la interpretación de Momigliano (1999: 206-210) es la más atinada. Él hace una lectura de la Historia de Heródoto como un ejercicio de comprensión de los persas.

${ }^{6}$ Cabe citar el comentario de Calvo Martínez (2007: 306), donde afirma que es el primer texto griego

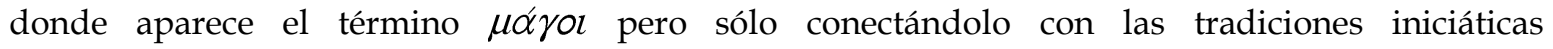
presumiblemente dionisíacas.
} 
Sin embargo, dentro de la literatura filosófica griega se mantiene la identificación del mago con el sabio persa, como un filósofo oriental cuya agudeza no necesariamente estaba por debajo de los helenos. Posiblemente debida a una tendencia "orientófila" presente en Grecia -iniciada con timidez desde el siglo VIII a.C. ${ }^{7}$ y vigente hasta pasado el Helenismo- puede entenderse la asimilación de la idea del mago-sabio. En dicho apego, no sólo lo persa fue estimado, sino también las tradiciones egipcias, hebreas ${ }^{8} \mathrm{e}$ indias. En lo que respecta a los persas, Momigliano (1999: 201 y 206) afirma:

Indudablemente es tentador explicar ciertos aspectos de los inicios de la filosofía griega a través de las influencias iranias. La repentina elevación del Tiempo a dios primitivo en Ferécides; la identificación del Fuego con la justicia, en Heráclito; la astronomía de Anaximandro, que sitúa a las estrellas más cercanas a la Tierra que a la Luna; estas y otras ideas nos traen a la mente teorías que nos han enseñado a considerar zoroastrianas, o en todo caso persas, o por lo menos orientales... Por extravagantes que se haga aparecer a los persas en Esquilo, no son bárbaros consumados, como los egipcios de Las suplicantes. Más enfático que Esquilo, Heródoto respeta a los persas y los considera capaces de pensar como los griegos9.

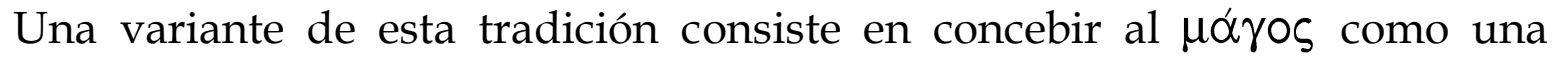
persona capaz de operar cambios extraordinarios en el medio ambiente, un iniciado ${ }^{10}$ que conoce secretos muy profundos del universo. Las diferentes

7 Cf. Feldman (1996). -El comentario de Álvarez Pedrosa (2008: 1002) sirve para matizar el vínculo político-cultural que se produjo entre griegos y persas a raíz de diversos hechos históricos: "...suscitaron un interés singular de la cultura persa entre los griegos, que oscilaba entre el aborrecimiento y la fascinación..."

8 Sobre este particular cf. el capítulo "El descubrimiento helenístico del judaísmo" en Momigliano (1999: 122-155).

${ }_{9}$ Álvarez-Pedrosa (2008: 1002-1012) es un poco menos entusiasta al momento hablar sobre los préstamos e influencias persas en la Hélade, no por ello, descarta la posibilidad de relaciones de ida y vuelta entre ambos pueblos. Su revisión se apega a la evidencia lingüística rastreable entre textos como los Gāthās y el Avesta, y diálogos platónicos, uno pseudo platónico (Axíoco), comedias aristofánicas y laminillas órficas. -Sobre la dignidad que Esquilo otorga a los persas Cf. García Novo (2005: 50-53).

${ }^{10}$ En este punto, Álvarez-Pedroza hace de nuevo una exhortación a la prudencia histórica, “...los autores tienden a considerar que el zoroastrismo es una religión de iniciados, aunque el concepto no se ajuste a los términos más rigurosos que se dan en la religión griega." (2008: 992, N. 4) -La magia como iniciación es una noción que se mantuvo vigente durante muchos siglos, por ejemplo,

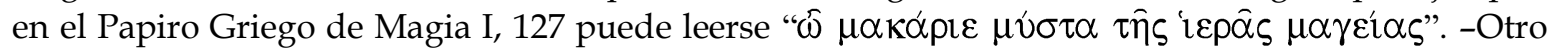
autor tardío, Numenio de Apamea, incurre en un apresuramiento cuando habla de la religión del antiguo Irán: “...los persas inician en los misterios adoctrinando al iniciado sobre el descenso de las almas y su subida y llamando [a este] lugar caverna. Según dice Eubolo, fue Zoroastro el primero que consagró en las montañas cercanas a Persia una caverna natural, florida y regada de fuentes, en honor a Mitra, creador y padre de todas las cosas, ya que la caverna le procuraba una imagen del 
fuentes griegas y romanas adjudican distinción de grado en las capacidades de los sabios orientales; las hay desde las que los hacen semidioses, hasta las más conservadoras que los muestran muy cercanos a la filosofía y la liturgia. Eudoxo ${ }^{11}$ y Aristóteles ${ }^{12}$ son quizá quienes más difusión dieron a la idea del mago-filósofo.

Filón de Alejandría (1977: XI), comenta sobre los magos:

En el mundo exterior, donde se hallan los que estiman las obras más que las palabras, encontramos amplias asociaciones de la más alta virtud y excelencia. Entre los persas está la orden de los magos, quienes investigan calladamente los hechos de la naturaleza13, a fin de alcanzar el conocimiento de la verdad, y por medio de visiones más claras que el lenguaje, dan y reciben revelaciones de la divina excelencia. En la India, también, existe la orden de los gimnosofistas, que estudian tanto la filosofía ética como la física y hacen de todas sus vidas una exhibición de virtud.

Por este camino sigue Apuleyo (2003: 26), expresándose de la siguiente manera:

Magia es en verdad lo que Platón entiende, cuando recuerda qué disciplinas inculcan los persas al niño destinado a reinar. Tengo en la memoria las palabras mismas de este divino varón, que tú Máximo puedes recordar conmigo: Cuando llega a los catorce años, reciben al muchacho aquellos que los persas llaman pedagogos reales. Son escogidos en número de cuatro, entre los persas de edad madura que gozan de mejor fama: el más sabio, el más justo, el más prudente y el más valeroso. Uno de ellos le enseña la magia [magei/an] de Zoroastro, hijo de Oromasdes. Ésta consiste en el culto de los dioses. Le enseñan también el arte de reinar. $^{14}$

Más adelante, Apuleyo hace otras referencias de la magia y los magos, e. gr.: en 26 critica la idea popular que consiste en creer que el mago es

mundo, el que Mitra fabricó, en tanto que los objetos en su interior dispuestos a distancias simétricas serían símbolos de los elementos y zonas del cosmos. Después del aludido Zoroastro la costumbre de celebrar sus iniciaciones en grutas y cavernas, naturales o artificiales." Fr. 60.

${ }^{11}$ Quien afirmaba que los magos eran "la más excelente y valiosa de las sectas filosóficas", además de datar el nacimiento de Zoroastro seis mil años antes de la muerte de Platón. Cf. Plinio, XXX, 5.

${ }^{12}$ Las reconstrucciones de su obra Sobre la filosofía recogen algunos comentarios al respecto, a saber: i) que los magos son más antiguos que los sacerdotes egipcios, ii) que hay dos principios regidores del universo: Arimano y Oromasdes y iii) proporciona otras fuentes que hablan sobre los magos: Hermipio Sobre los magos (este dato se encuentra también el Plinio, XXX, 4), Eudoxo Viaje y Teopompo, Filípicas VIII. Cf. D.L. I, 8. Sobre la opinión que Aristóteles tenía de los sabios orientales, recuérdese que en Metafísica 918b 21-23 también habla de los sacerdotes egipcios.

${ }^{13}$ El subrayado es mío. Nótese cómo describe a los magos.

${ }^{14}$ Las palabras citadas de Platón aparecen en griego en medio del texto latino. 
omnipotente gracias a que se vale de conjuros y cánticos dirigidos a los dioses; en 31 alude una creencia compartida por "muchísimos" consistente en considerar a Pitágoras seguidor de Zoroastro y diestro en la magia; en 38 menciona cierta creencia de su tiempo que vincula a los babilonios y egipcios con ensalmos y conjuros; en 40 establece con cautela vínculos entre el filósofo, el médico y el mago, siendo el conocimiento de la naturaleza el común denominador entre los tres. Por último, en 90 cita un catálogo de magos eminentes compuesto por Carmendas, Dárdano, Moisés, Iannes, Apolobex, Ostanen y Zoroastro15.

Encontramos un par de entradas en la SUDA, posiblemente influidas por tradiciones neoplatónicas y pitagóricas tardías, en las que se toca el tema de los magos. En $\Delta, 447$ se habla sobre Demócrito enlistando sus mentores:

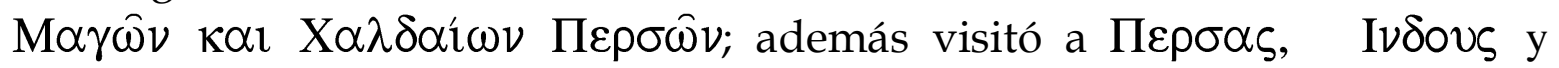
Air $v \pi \tau i ́$ ovs de quienes tomó lo mejor de su sabiduría para esparcirla entre los griegos. En $\zeta, 159$, dedicada a Zoroastro, se le define como un $\sigma 0 \phi 0 \varsigma^{16} \mathrm{y}$

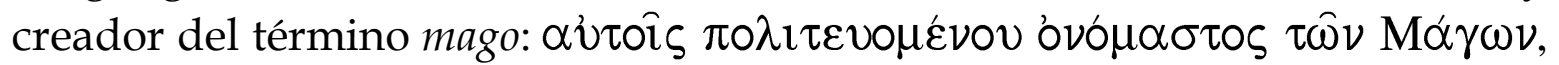
datando su existencia histórica quinientos años antes de la guerra de Troya.

Los célebres Oráculos caldeos constituyen una fuente importante para comprender la transmisión del término mago. En ellos confluyen elementos de un neoplatonismo muy particular con matices gnósticos y pitagóricos, una fuerte orientofilia, así como tintes de religiones mistéricas griegas, en particular el orfismo y los cultos eleusinos. Los Oráculos suelen traslapar el término $\chi \alpha \lambda \delta \alpha i o s$ con $\mu \alpha \gamma \gamma^{17}{ }^{17}$. El primero vinculado con tradiciones babilónicas relativas al conocimiento físico y espiritual de las estrellas, la adivinación, la interpretación de los sueños y, en algunos casos, con el manejo de ensalmos capaces de alterar el funcionamiento de la naturaleza. Según la tradición erudita bizantina, fue Juliano el Teúrgo ${ }^{18}$, hijo de Juliano

\footnotetext{
${ }^{15}$ A propósito del texto de Apuleyo, donde se defiende contra acusaciones por practicar magia, debe mencionarse que dentro del egipcio copto el término hik, derivado de hkß pasó al ámbito jurídico grecorromano interpretado como "impius and ilegal sorcery" Cf. Ritner (2001: 321). Aunque, cabe mencionar que, simultáneamente, en otros círculos se le consideraba a la magia $\theta \varepsilon i \alpha$

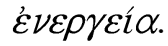

16 Según el diccionario bizantino, su saber destacaba especialmente en astronomía, aunque su conocimiento de la naturaleza era muy amplio. -Según afirma Bremmer (1999: 5), Janto de Lidia fue el primer griego que mencionó a Zoroastro.

${ }_{17}$ ¿Paralelos con SUDA D, 447 ?

18 Cf. SUDA, l 434. -En el artículo se mencionan detalles que lo insertan en la tradición orientalizante greco-romana de época a caballo entre el final del Helenismo y el inicio de la Antigüedad Tardía. V. gr.: se le adjudica la redacción de un par de obras, $\Theta \varepsilon v p \gamma \iota \kappa \alpha, T \varepsilon \lambda \varepsilon \sigma \tau \iota \kappa \alpha$, así como unos textos que se han interpretado tradicionalmente como los Oráculos, $\Lambda$ ó
} 
el Caldeo $(\chi \alpha \lambda \delta \alpha i ̂ s)^{19}$, quien compiló los célebres Oráculos. El comentario de García Bazán en la introducción de los Oráculos caldeos (1991: 14-15), clarifica la visión que entonces se tenía de los caldeos y los magos:

Los caldeos constituían tanto una agrupación iniciática dirigida por sus hierofantes, en este caso concreto Juliano el Caldeo, como practicantes de ritos y conservadores de doctrinas, indicadas por símbolos orales (los lógia di'epôn o fórmulas versificadas) y físicos, de naturaleza tradicional, es decir, de origen divino y regularmente transmitidos, para poder poseer un carácter eficaz o teúrgico. Este tipo de asociación mistérica está emparentada en su aspecto litúrgico y en los puntos fundamentales de sus creencias... con los magos (mágoi) anatólicos de origen medo-persa, una vez configurada cosmográficamente su doctrina por la ciencia astral del clero babilonio... Es también común a los miembros de estos grupos esotéricos la incorporación de rasgos propios de las prácticas de los magos-caldeos en tierras siríacas (trashumancia ramificadora y uso de encantos y conjuros), así como la adopción filosófica de un platonismo difuso, pero de orientación pitagorizante.

Dado que la Hélade fue una sociedad viva, hemos de entender que el idioma era cambiante y estaba en constante movimiento, los significados de $\mu \alpha \dot{\alpha} \sigma \varsigma$ no estaban consensados, dándose al mismo tiempo acepciones denigrantes y meritorias, su uso dependía de la comunidad. En una dimensión peyorativa se le emparenta con róns (hechicero, brujo, mago 20 , embaucador, charlatán,

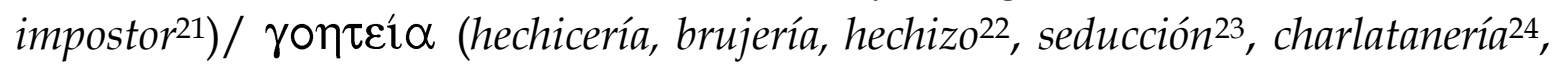

¿Estará entendiéndose '̇ $\tau \hat{\omega} v$ entremezclando su conexión con la antigua épica heroica (una forma de rendir culto a los muertos) y con los conjuros? Dentro de este mismo artículo se narra que Juliano hizo llover mediante un saber secreto, sin embargo, también se dice que algunos adjudicaban a Apvovфis, un filósofo egipcio, tal maravilla. De nuevo aparecen elementos de la mentalidad de la época, es difícil determinar hasta qué punto nos encontramos ante una tendencia orientalizante y en qué medida se narran hechos y personas reales.

19 Cf. SUDA, l 433, -El Caldeo es definido como filósofo, se menciona una obra suya sobre los daímones, compuesta por cuatro libros.

${ }^{20}$ Calvo Martínez señala sobre el término yóns: “...muy a menudo sirve como insulto, es una palabra siempre cargada de valores puramente negativos..." (2007: 304) -Estas tres acepciones pueden encontrarse en Historia II, 33 de Heródoto; Hipólito, 1038 y Bacantes, 234 de Eurípides; en República, 380d de Platón; en Marco Aurelio Antonino, 1,6; Historia de los animales de Eliano, III, 17; y, Eneadas, IV, 4, 40 de Plotino.

${ }^{21}$ Con estos significados puede encontrársele en Banquete 203d de Platón. En Demóstenes XVIII,

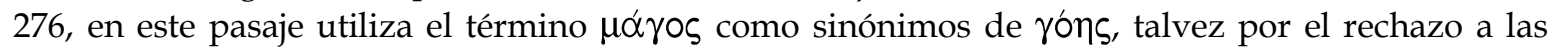
importaciones de imperios hegemónicos como lo fue primero el persa y luego el macedonio. En Preparación al Evangelio V, 18,6 de Eusebio. En un fragmento de un papiro erótico griego, Hermes, 55, 1920,191; en 77/78, 33 de Dío Crisóstomo; en Oraciones XXVIII, 11 de Arístides, y en Contra Celso II, 49 de Orígenes. En Edipo rey, 387 parecería tener dicha acepción, sin embargo Clavo Martínez considera que se trata de una referencia a los magos persas (1999: 308-309). 
atracción engañosa ${ }^{25}$ ). Se le vincula también con $\varepsilon \pi \omega \delta \varsigma^{26} \varsigma^{2}$ (conjurador, quien

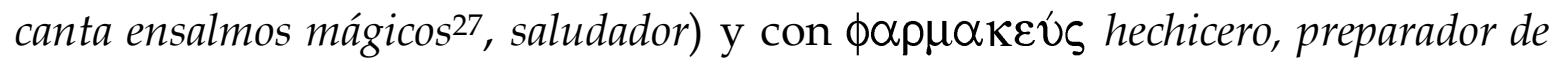

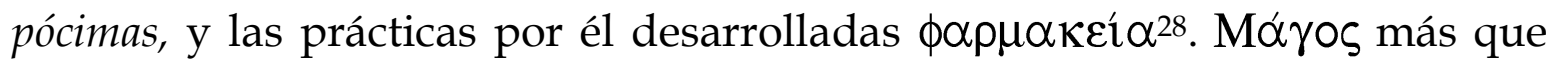
ser un término cuyo sentido fue perdiendo su significado original al pasar de los siglos, fue una palabra que sumó giros, dependiendo de los propósitos de los autores. Sin embargo, cabe puntualizar que no es tan sencillo identificar a la magia y al mago con la irracionalidad, las tradiciones populares, creencias supersticiosas o la charlatanería sin explicar toda la complejidad que envuelve la recepción del concepto en nuestras lenguas contemporáneas. El cristianismo contribuyó significativamente a fijar el sentido de magia en tanto que una práctica pseudoreligiosa contraria a los mandamientos. El islam, debido a sus raíces cristianas, adopta en parte dicha concepción ${ }^{29}$; en árabe سحر (sḥr), magia, reúne las acepciones peyorativas ya expuestas. Sin embargo, existe una aleya (II, 102) que nos invita a poner atención especial en la transmisión del concepto:

Siguen lo que practicaron los demonios en el reinado de Sulayman. Pero no fue Sulayman quien cayó en la incredulidad, sino que fueron los demonios al enseñar a los hombres la magia que le había sido revelada a los dos ángeles...

La magia constituye el saber de misterios que no pueden ser revelados al hombre, cuando esto sucede se comente una transgresión de los límites

${ }^{22}$ Cf. Gorgias B 11,10, donde se le hace sinónimo de $\mu \alpha \nu \tau \varepsilon i ́ \alpha ;$ Banquete 202e y República 582a de Platón; en Crisipo, III, 96, y Eneadas IV, 4, 43 de Plotino.

${ }^{23}$ Cf. República, 413d de Platón; Iambi ad Seleucum, 179 de Anfiloquio y Cartas a Ático, 180, 4 de Cicerón.

${ }^{24}$ Cf. Sobre la enfermedad sagrada, XXI, 26, dónde se le hace paralela a las purificaciones fraudulentas.

${ }^{25}$ Cf. Eneadas, IV, 44, 4 de Plotino y Stromata, II, 20, 120 de Clemente de Alejandría. -Emparentado posiblemente con el término $\psi \eta \phi о \pi \alpha i ́ \kappa \tau \eta \varsigma$ "prestidigitador", que luego será una forma de referirse a los magos egipcios contra los que Moisés se enfrentó.

${ }^{26}$ Deriva del término ع̌̃os, palabra, narración, canto a los héroes.

${ }^{27}$ Dentro de la literatura tardía, pueden encontrarse diferentes clases de conjuros, $\dot{\varepsilon} \pi \omega \delta \eta$, a saber: para alejar un mal, PGM XX, 5 y 13; ensalmo para pedir la intervención de un dios a través de un daimon, PGM, I, 296 y 317, hechizo con fines eróticos, PGM, IV, 295, VII, 992 y XX, 3.

28 Sobre este término, Kingsley (2008: 295) comenta: “...la palabra pharmakon poseía también la acepción de "encantamiento", y en el caso del fragmento empedocleo [Diels, III] designa los remedios, pero también, de modo implícito, los conjuros ( $\varepsilon \pi \omega \delta \alpha \hat{\imath})$ que eran recitados durante la

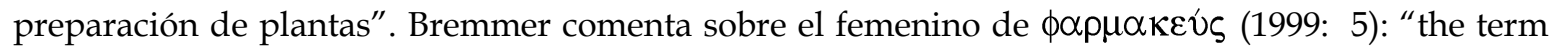
pharmakis was probably once limited to a woman who collected herbs for magic, but gradually in must have absorbed (or: benn ascribed) qualities from the male sorcerers".

${ }^{29}$ En el Noble Corán pueden encontrarse diversas aleyas en las que la magia es vista como charlatanería o prestidigitación, por ejemplo: VI, 8, VII 108, 111 y en 115 se juega con los sentidos del término llevándolo de lo maravilloso a la prestidigitación. X, 77, XI, 7, XX,56, XXI, 3, XXV, 8, XXVI, 33 y 34, 36 y 37, 39 y 40, 45; XXVII, 13, XLIII, 29, LI, 39, LII, 13, LIV, 2, LXI, 6 y LXXIV, 24. 
impuestos por Allāh, empero, el sufismo contempla el conocimiento moderado de dichos secretos. Las observaciones de Ibn Jaldún sobre el tema sirven para clarificar parte de la interpretación de la سحر dentro del islam. Afirma (2011: 927)

\begin{abstract}
"los hombres de sólida inteligencia jamás han tenido la menor duda respecto a la existencia de la magia. Han advertido los efectos que ella produce... [empero] La ley divina no hace ninguna distinción entre la magia, el arte talismánico y sus respectivos influjos; todo lo incluye dentro de las cosas proscritas. (p. 933)." La excepción la constituyen los sufistas, quienes "...por un don de Dios, desarrollando la facultad de ejercer una influencia sobre las cosas del mundo, influencia que no debe confundirse con la magia [porque ésta es animada por los demonios] (p. 932)”30.
\end{abstract}

Podría aventurarse una distinción con Ibn Jaldún, pues, entre magia negra y "magia blanca".

\title{
La 1 in
}

Uno de los aspectos más importantes que hay que tomar en cuenta para abordar el pensamiento egipcio, es asumir que carecemos de las categorías culturales que logren captar con total precisión la naturaleza de tradiciones y prácticas tan arraigadas. Es frecuente prejuzgar a los egipcios, tildándolos de ser extremadamente religiosos, al extremo de profesar una superstición ingenua. Se les llega a definir pragmáticos siendo lo contrario de la "mentalidad griega", dedicada a la teorización. Para iniciar con el ejercicio de traducción cultural, quisiera evocar el caso del olimpismo citado páginas atrás. ¿Aceptaríamos que fuera encasillado por estudiosos foráneos sólo en el campo de los negocios, de la política, de la tecnología? En realidad, es una mezcla de todo, lograda en el contexto de un mundo "democrático" y "libre". De la misma manera, debe actuarse con prudencia cuando se habla del antiguo Egipto, aunque sus matemáticas y liturgia parezcan cercanas a las nuestras, es necesario comprenderlas en el marco que se dieron. Wieleitner (1927: 13) cuestiona nuestro entendimiento de la "ciencia" egipcia:

\footnotetext{
${ }^{30}$ La sección VI, 22 de Al-Muqaddimah está dedicada a la desacreditación de la magia demoníaca, exhibiéndola como una práctica que se vale de talismanes y cuyas fuentes pueden ser, la manipulación maligna, la prestidigitación o la persuasión psicológica. También es importante señalar que Ibn Jaldún identifica a caldeos, asirios y coptos como los practicantes de la talismánica de la Antigüedad.
} 
Wenn man die Wissenschaft der alten Ägypter als "praktisch" oder "rein empirisch" hinstellt, wird man in vielen Fällen natürlich nicht Unrecht haben. Jedoch scheint mir damit meist ein Unterton des Herabsetzenden verbunden zu sein, den ich nicht für berechtigt halte.

Si con la "ciencia" egipcia tan "cercana" a nuestra mentalidad occidental hay problemas para encuadrar con precisión su dimensión original, mayor será la complejidad para entender la empezar, considero pertinente puntualizar que no existe una palabra en egipcio jeroglífico que corresponda a lo que nosotros entendemos por magia ${ }^{31}$, tampoco había un paralelo de la $\mu \alpha \gamma \varepsilon i ́ \alpha$. El vocablo contiene dos componentes que es menester revisar.

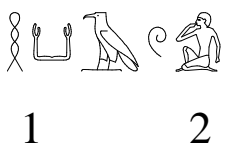

1) $k$ 3: brazos, posiblemente en gesto de alabanza, se conectan con la idea de adoración, quizá hasta algo cercano a la contemplación; pero, también, con una "energía espiritual personal-cósmica", Betrò comenta: "...eine Lebenskraft, die sowohl Menschen wie Götter besitzen. Er überträgt sich vom Vater auf den Sohn und gehört, da er mehr ist als ein Element der individuellen Persönlichkeit." (2004: 58) 32 .

2) determinativo que tiene que ver con actividades vinculadas con la boca: hablar, callar, beber, comer, contar. También se relaciona semánticamente con aspectos relativos al pensamiento y al gusto. En el caso de la $h k 3$ se relaciona con pronunciar conjuros, no sin dejar de lado el aspecto cósmico que los fundamenta y valida. En TdP encontramos una frase que refleja el poder del conjuro: "Whenever I speak to you, gods, you see and hear my speech." (Pared norte, antecámara, 753).

Es frecuente que se establezcan vínculos apresurados identificando sin más un conjuro o un exorcismo con la $h k^{33}$. Ritner (2001: 321-336) apunta algunas

\footnotetext{
${ }^{31}$ Existía vocabulario de "expresiones mágicas", por ejemplo l dios, criticar. rituales secretos $\subset$ - $\left(m t^{\circ}\right)$ ritual o $\quad$ (shri) exorcizar.

${ }^{32}$ La $h k 3$ constituía un factor para definir la identidad de la persona, así puede verse en Textos de las Pirámides (TdP), Unis, corredor-paredes oeste y este, 316; TdP, Pepi I, pared oeste de la antecámara, 472; TdP, Pepi I, pared sur del vestíbulo, 539.

${ }^{33}$ Hans Fischer, dentro de su estudio introductorio a textos mágicos egipcios (2005: 9), comenta sobre el problema para interpretar la "magia egipcia": "Im Deken der Alten Ägypter hat der Demiurg seinen Geschöpfen neben anderen elementaren Dingen wie Luft, Nahrung, Himmel und
} 
acepciones que facilitan la traducción cultural: i) "force that once animated, compeled, and protect the gods and subsequent creation ${ }^{34}$. Antecedent to the

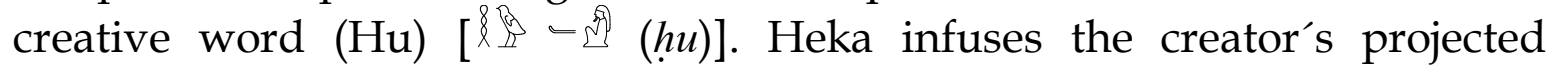
images or ka-spirits, with his "magical" vitality" ${ }^{35}$. En ocasiones es personificada ${ }^{36}$, un ejemplo muy claro es Libro de los Muertos (LdM) 84: Faulkner traduce: "I don't know the magician, but I hear his words", las siguientes versiones coinciden en la idea central: Budge: "I know Heka, I hear his words", Lara Peinado "No conozco (tampoco) a Heka, (si bien, solamente) oigo sus palabras mágicas", Barguet: "no conozco a Heka, oigo (solamente) sus palabras mágicas". La ḥk está compuesta, según, Ritner, por tres elementos constitutivos, a saber: el habla (conjuro), las propiedades inherentes ${ }^{37}$ (comprensión del ente y las condiciones que lo rodean, ¿una de las posibilidades del $k$ ? ?) y el rito (acto de vinculación con los principios que rigen el cosmos). Quizá ésta sea una de las interpretaciones que más nos interese, dado que aquí está impreso un proyecto cósmico, pudiendo tener conexiones con nuestra idea de estética (teoría de la harmonía) y metafísica (teoría sobre la Realidad). El proyecto cósmico está marcado por $(M 33 t)^{38}$, síntesis de orden expresado en la legalidad, la belleza, la salud y el equilibrio. De tal forma que la $h k \jmath$ no es un principio sobrenatural arbitrario, debiéndose adaptar a las proporciones y ritmos que rigen la Realidad. Allen, en su léxico comentado TdP, señala: "The term $h k 3$ generally refers to the force itself, while $h k 3 w$ [mago] denotes the medium through wich the force is excersised, usually "magic spells" (2015: 360). ii) Rituales y conjuros que

Erde sowie einem Königtum als ägyptisch hekaw und im späteren Koptisch hik lautet. Diesen Begriff übersetzen wir Modernen leichtfertig, wie "Zauber" oder "Magie", ohne dabei zu bedenken, wir sehr westlichem Deken klassisch-antiker und besonders jüdisch-christlicher Prägung verpflichtet sind"

${ }^{34}$ Cf. TdP, Teti, cámara funeraria, 324.

${ }^{35}$ Cf. Textos de los sarcófagos, 261.

${ }^{36}$ A propósito de la personificación de la $h k 3$, a algunos dioses se les identificaba con el epíteto "El Grande de la $h k$ ”" o "El Gran Mago" (wrt-hk3w), regularmente eran Seth y Horus a quienes se les asignaba dicho título, sin embargo, no eran los únicos en recibirlo. Cf. TdP, Pepi I, cámara funeraria, lado sur, 220, 222, y extremo oeste de la cámara funeraria, 443; TdP, Merene, extemo oeste de la cámara funeraria, 592. - En Pepi II, en la pared norte de la antecámara, 692 B se le llama a Thot "Señor de la Magia".

37 James (2001: 76) afirma al respecto: “The Doctrines of the universal distribution of the atoms, and their emanation from external objects are derived from magic: These doctrines are magical and express the magical principle "that the qualities of animals or things are distributed throughout all their parts."

38 Para tener una perspectiva más clara de $M 33 t$, Cf. LdM, 15 (vinculada con la magia como poder protector), 31 (ritmo), 39 (destrucción), 41 (justicia), 50 (creación del mundo), 79 (purificación moral del difunto), 130 (equilibrio integral del individuo), 145 y183 (justicia y verdad), 165 "País de M33t,“ (el Más Allá, tierra de los justos). 
tenían como objetivo alterar el orden de las cosas, destruir enemigos ${ }^{39}$, alterar la apariencia para evadir los ataques de genios en el Más Allá40 o atraer al ser deseado o amado ${ }^{41}$. Lo anterior era sólo una de tantas aplicaciones que podía tener la fuerza neutral $h k$ s, es decir, no existía una concepción de magia negra o blanca. La mayoría de los textos que plasman rituales y ensalmos datan de época tardía 42 , por lo que es muy difícil saber a ciencia cierta la manera en que se produjo la fijación de tradiciones ancestrales en soportes materiales. iii) Emanación de $\mathrm{Ra}(b 3 w)$ que acompañaba actividades como la agricultura, la medicina, los rituales de estado, la arquitectura (fundación de ciudades y erección de construcciones). iv) la 1 funeraria aplicada en la conservación de cadáveres por medio del embalsamamiento $\_(w t)$, compuesto por un momento material y otro de procesos "espirituales", "sobrenaturales", "divinos" -por expresarlo de alguna manera-. El sacerdote funerario recitaba ensalmos y conjuros a la par de tratar al cadáver con elaborados métodos de preservación en los que se veían involucrados saberes que hoy ubicaríamos en la química, la biología y la medicina ${ }^{43}$. El cuerpo momificado era, según la mentalidad egipcia, la herencia sagrada obsequiada por los dioses -particularmente por Osiris-; era, arriesgándome a cometer una trasgresión cultural, el misterio por excelencia que daba significado a rituales y pensamiento egipcios. En un pasaje de los TdP (Cámara funeraria de Unis,

\footnotetext{
39 Se ha conservado un volumen importante de textos destinados a ahuyentar animales peligrosos. A continuación unos ejemplos: Fórmulas contra las cobras, conjuros 226, 228 y 230 TdP, Unis. Fórmula contra las serpientes, contenida en el P. de Turín 54003, conjuro III (ca. 2000). El P. del BM 9997 contiene conjuros contra serpientes que deben usarse con un amuleto de fayenza. Hay una imagen del papiro disponible en: http://www.britishmuseum.org/research/collection_online/collection_object_details.aspx?objectI

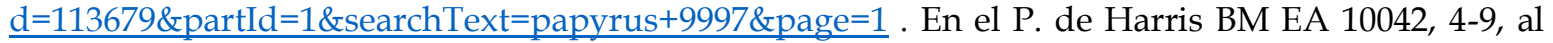
final de un himno -nótese la complejidad para clasificar los textos en nuestras categorías literariasaparece un ensalmo que ahuyenta cocodrilos del río y leones del desierto.

${ }^{40}$ Esto hizo que algunos estudiosos pensaran que los egipcios creían en la reencarnación en organismos animales.

41 Por ejemplo, un conjuro de amor escrito en el óstrakon Deir el Medina 1057 (ca. 1100 a.C.).

42 E. gr.: el Papiro Bremner Rhind, perteneciente BM, EA 10188, 17 (Cantos de Isis y Neftis) datado en el 350 a.C., puede verse una imagen del papiro en https://www.britishmuseum.org/research/collection_online/collection_object_details.aspx?object

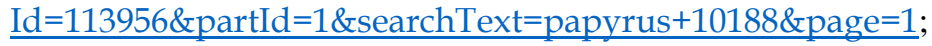

43 Budge (1988: 185) comenta al respecto: "But for an account of the manner in which the body was bandaged, and the list of unguents and other materials employed in the process, and the words of power which are spoken as recourse to a very interesting papyrus which has been edited and translated by M. Maspero under the title of Le Rituel de l'Embaumement. The first part of the papyrus, which probably gave instructions for the evisceration of the body in wanting..."En TdP Unis, faldete y pared este, 273-274 se habla ingerir la $h k 3$ como una de las cosas que debe hacer quien pretenda ser inmortal en el Más Allá.
} 
lado sur, 213) encontramos un conjuro que involucra la consagración del cuerpo:

Ho, Unis! You have not gone away dead: you have gone away alive. Sit on Osiris' chair, with your baton in your arm, and govern the living with your lotus scepter in your arm, and govern those of the remote places.

Your lower arms are of Atum, your upper arms of Atum, your belly of Atum, your back of Atum, your rear of Atum, your legs of Atum, your face of Anubis ${ }^{44}$.

v) Un sentido implícito que tenía la $h k 3$-conjuro, es ser una especie de historia oral en la que se recogen evidencias de la relación con pueblos extranjeros o de un léxico obsoleto que se conserva en expresiones ininteligibles que revisten de misticismo las palabras del mago. Lewis Spence (1990: 265) comenta:

A great many of these seemingly nonsensical spells consist of foreign words and expressions, some of them of Syrian origin. It is well know that the shamanistic class in savage communities is prone to invent a secret language or dialect of its own, and that the vocabulary of such a jargon is usually either archaic or else borrowed from the neighbouring language. ${ }^{45}$

44 Una consagración del cuerpo más detallada puede encontrarse en LdM, XLII: "My hair is Nun; my face is Re; my eyes are Hathor; my ears are Wepwawet; my Nose is Shu who presides over her lotus-leaf; my lips are Anubis; my molars are Selket; my incisors are Isis the goddess; my arms are the Ram, the Lord of Mendes; my breast is Neith, Lady of Sais; my back is Seth; my phallus is Osiris; my muscles are the Lords of Kheraha; my chest is He who is greatly majestic; my belly and my spine are Sakhmet; my buttocks are the Eye of Horus; my thighs and my claves are Nut; my feet are Ptah; my toes are living falcons; there in no member of mine devoid of a god, and Thot is the protection of all my flesh." -En TdP, Pepi I, pared sur del vestíbulo, 539, encontramos un conjuro similar.

${ }^{45}$ Se han conservado diversos textos egipcios en los que aparecen palabras que los estudiosos no logran descifrar, términos que cayeron en desuso o son, posiblemente, parte de un "léxico mágico" cuya etimología se remonta a idiomas arcaicos. En el P. de Leiden I, 348, 4,1 se menciona un tejido nedj, en 8,6 se habla de la sangre del pez 3bdju. En el P. BM 10059, 5 (ca. 1200 a.C.) puede leerse lo siguiente: "Beschwörung der Asiaten (krankheit) bestehend aus dem, was Kreta dazu (=zur Beschwörung) sagt: s-n-t-k-p-p-w-y-j-y-m-n-t-r-k-k-r". Puede verse una imagen de este papiro en http://www.britishmuseum.org/research/collection_online/collection_object_details/collection_i mage_gallery.aspx?assetId=35790001\&objectId=110335\&partId=1. En el LdM se refieren varios nombres mágicos (secretos) de los dioses, por ejemplo 165, 166, 167. En el P. BM 9997, VI 2, se refiere una serpiente de nombre schepu-ib. -En el P. Edwin Smith XXI, 9 se menciona la fruta $h m 3 y t$ que no logra ser identificada. En sus comentarios, Breasted sugiere que puede tratarse de una nuez (p. 496). En el mismo texto, XX, 8 se menciona la planta šms.-En TdP, Teti, pared este de la antecámara, 377 se habla de la serpiente $h p j w$ y se identifica al difunto con una fuerza llamada 
vi) Los conjuros como terapia médica. ${ }^{46}$ Suponemos que los egipcios creían en la efectividad de los conjuros, sin embargo, se especula cuando se les reduce a mera superstición. Según los registros que se han conservado, la palabra mágica acompañaba a procedimientos médicos en casos como mordedura de ofidios, padecimientos de la matriz o en el combate a la infertilidad. Era frecuente también que se empleara en padecimientos psicosomáticos o en otros que no eran muy bien conocidos, como las pestes ${ }^{47}$. Los facultativos egipcios sabían reducir fracturas, hacer cirugías y prescribir remedios en base a la farmacopea; su práctica no tenía los avances tecnológicos que hoy disfrutamos, no por ello, podemos considerar que sus terapias pecaban de candidez o pereza mental.

\section{A manera de conclusión}

Considero que la actitud más pertinente que puede seguirse con la es mantenerla apegada, en lo posible, al contexto donde se produjo. Introducirla a nuestra escala espiritual evolutiva, en un peldaño por debajo de la religión, es atentar contra su unidad originaria. Sin embargo, al llevar a cabo una traducción cultural, cabe la posibilidad de encontrar puntos de coincidencia con nuestra idea de filosofía, sin reducirla a ella. La $h k 3$ estaba constituida a partir de una axiología que no es compatible con la occidental, no lo es porque constituya un abandono a la reflexión crítica del mundo, sino porque sus propósitos fundantes parten de una sensibilidad diferente ${ }^{48}$.

$\underline{d}^{\top} \mathrm{r} m w, 382-383$. -TdP, Pepi II, extremo este de la cámara ritual, 180-191, contiene una serie de palabras mágicas para nombrar vasijas y panes.

${ }^{46}$ Cf. P. de Leiden I, 348, 3,8-8,7. (ca. 1200 a.C.) donde se compendian cuatro conjuros contra la migraña y un exorcismo para sacar los demonios que atormentan al paciente. -En el P. de Atenas 1826, 7,11-8,5 (ca. 1200 a.C.) se recoge un conjuro contra una "enfermedad extranjera y demonios", posiblemente una clase de peste; así comodos ensalmos para ser pronunciados con amuletos, destinados a resolver el mismo padecimiento.

47 En el de P. Edwin Smith hay una pequeña sección (XVIII-XX) integrada por ocho encantamientos (exorcismos) contra la peste del año, destinados de combatir el viento maligno, una especie de peste periódica que cada año volvía a causar estragos entre la población. ¿Podríamos estar ante purificaciones colectivas, "medicina social", profilaxis, higiene en su sentido etimológico más lejano?

${ }^{48}$ Egipto, al igual que otras grandes civilizaciones de la Antigüedad, no puede ser limitado a un puñado de aspectos culturales ni a una tipología racial única. Existía un Egipto negro, uno con raíces en Anatolia, otro mediterráneo, constituyendo cada uno un pequeño universo en miniatura. Respecto del Egipto negro, y, en general de la negritud africana, el ensayo de Souleymane Bachir Diayne (2011) nos invita a pensar en la estructura que guía mentalidades distintas a las nuestras. "...the expression of African philosophy itself, that is to say, the way of seeing, thinking and feeling that integrates fields of human activity as different as medicine, law, religion, logic and wisdom by serving as raison $d^{\prime}$ être and the key to truly understanding them. Among these fields, artistic 
James (2001: 103) considera: "Magic is the key to the interpretation of ancient religions and philosophy." Más adelante dice

"...since it was the method of the Egyptians to conceal the truth by the use of myths, parables, magical principles (primitive scientific method), number philosophy and hieroglyphics, we can easily see what methods might be involved before we could arrive at better translation of the Memphite Theology" (p. 147).

Desde su creación en la Hélade, la palabra $\mu \alpha \gamma \varepsilon i ́ \alpha$ es insuficiente. Primero, para captar lo que hacían los persas, luego al aplicarla a la dándole una fuerte carga de platonismo pitagorizante. Es necesario reconsiderar el papel que juega un esquema tan complejo dentro del tejido multicolor de los pueblos antiguos. Podemos o no estar de acuerdo con los prolegómenos que apoyaban esta manifestación cultural, pero, merece la pena estudiar algo que estuvo tan arraigado en aquellos siglos. Para expresarlo de alguna manera, la revisión de los vestigios egipcios que han llegado a nosotros, dan razones suficientes para creer que la era un componente importante de la identidad nacional. Entendida en diferentes niveles y asignándole varios roles, según la clase social que la cultivara. Así como los hebreos asignaban valor múltiple a sus profetas, como los babilonios concebían la metalurgia, como los griegos hacían teatro, o como los germanos fincaban sus sociedades en la guerra; así, la para los egipcios esencial en su vida.

Al revisar el pensamiento egipcio en busca de "filosofía", se tocan casi siempre los mismos temas ${ }^{49}$. No se llega más lejos de comentarios mecánicos de las cosmogonías, impresas en las teologías llegadas nosotros. El común denominador es ubicarlas en el terreno de la religiosidad exagerada $\mathrm{y}$, en los casos más moderados, calificarlas de preciencia, prefilosofía o pensamiento racional embrionario. Sin embargo, conceptos como la son simplificados al ámbito religioso sin abrir la mente para explorar sus

activity is primary, even before religion: because, where orality reings, art constitutes the writing which allows us to read the metaphysics it transcribes" (p. 54). Cita unas palabras del filósofo Sénar Senghor: "What is rhythm? Is the architecture of being, the internal dynamism that gives it form, the system of waves it gives off toward Others, the pure expression of vital force. Rhythm is the vibrating shock, the power which, through the senses, seizes us at roots of our Being. It expresses itself through the most material and sensual means: lines, surfaces, colors, and volumes in architecture, sculpture and painting, accents in poetry and music; movements in dance. But it doing this, it organizes all this concreteness toward the light of the Spirit. For the Negro African, it is insofar as it incarnate in sensuality that rhythm illuminates the Spirit." (pp. 78-79)

${ }^{49}$ Hornung (2000: 113-115) es de los pocos egiptólogos que aborda con más de detalle la esencia e historiografía del pensamiento egipcio. 
posibilidades y fundamentos que los articulaban. Asante (2000: 1-12) revisa con atención los prolegómenos del pensamiento nilótico:

\begin{abstract}
It is not trite for the African to say: "everything is everything". And to the mind of the ancient Kemetic [Egyptian] people this idea was thought to represent the whole universe as one. From the beginning it was oneness of everything that became the key with which the Egyptian mind unlocked many secrets of the world. Thus, one's world, whether from the personal or the collective perspective, was based upon the actual quest to make the world one, to establish the interconnections of all things, to reconstruct the universe as it was in the beginning (pp. 2-3).
\end{abstract}

Cualquier texto o discurso que sea estudiado aisladamente conducirá a una visión distorsionada de sus autores. Las reputadas Críticas de Kant, los escritos de fenomenología de Husserl o las meditaciones de Antonio Machado, no están exentas de tales lecturas. Cualquier escrito puede ser reducido a "mera literatura", letra muerta -según el giro denigrante que le han dado algunos filósofos contemporáneos a la expresión-. Los conjuros egipcios son el blanco de tal simplificación; aun si la sólo se compusiera por dichas piezas, merecería un tratamiento más completo y tolerante. A menudo se pierde de vista que las "palabras mágicas" pertenecían a un complejo sistema de ideas donde lo divino, lo natural y lo humano convivían estrechamente. Un esquema de ideas que debería considerarse tan digno como el producido por Platón y Aristóteles, sólo que acotando las claras diferencias que los distinguen. Para nuestra mentalidad significa un esfuerzo titánico imaginar que existen otras maneras de pensar, equipadas con otros cimientos y propósitos. Aquí surge la pregunta incómoda ¿qué tan plural es nuestra filosofía?

¿Por qué no emprender un ejercicio de traducción cultural como el que se ha

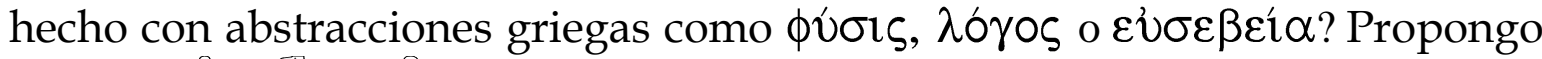
que a la se le dé el calificativo de "afilosófica", por tener una naturaleza diferente a nuestras ideas de filosofía y evadiendo la actitud de "dignificarla". Lo que no implica que no plantee reflexiones esenciales como la idea de unidad, existencia, divinidad, humanidad -condición de ser humano-, lenguaje, equilibrio, ritmo, "religión", orden, "naturaleza" o "energía", entre muchas más. En estas coordenadas es a donde debemos dirigir nuestra atención. Quizá los filósofos griegos tuvieron más acercamiento con esta manera de pensar de lo que estamos dispuestos a aceptar. 


\section{Apéndice: lenguas habladas por los persas}

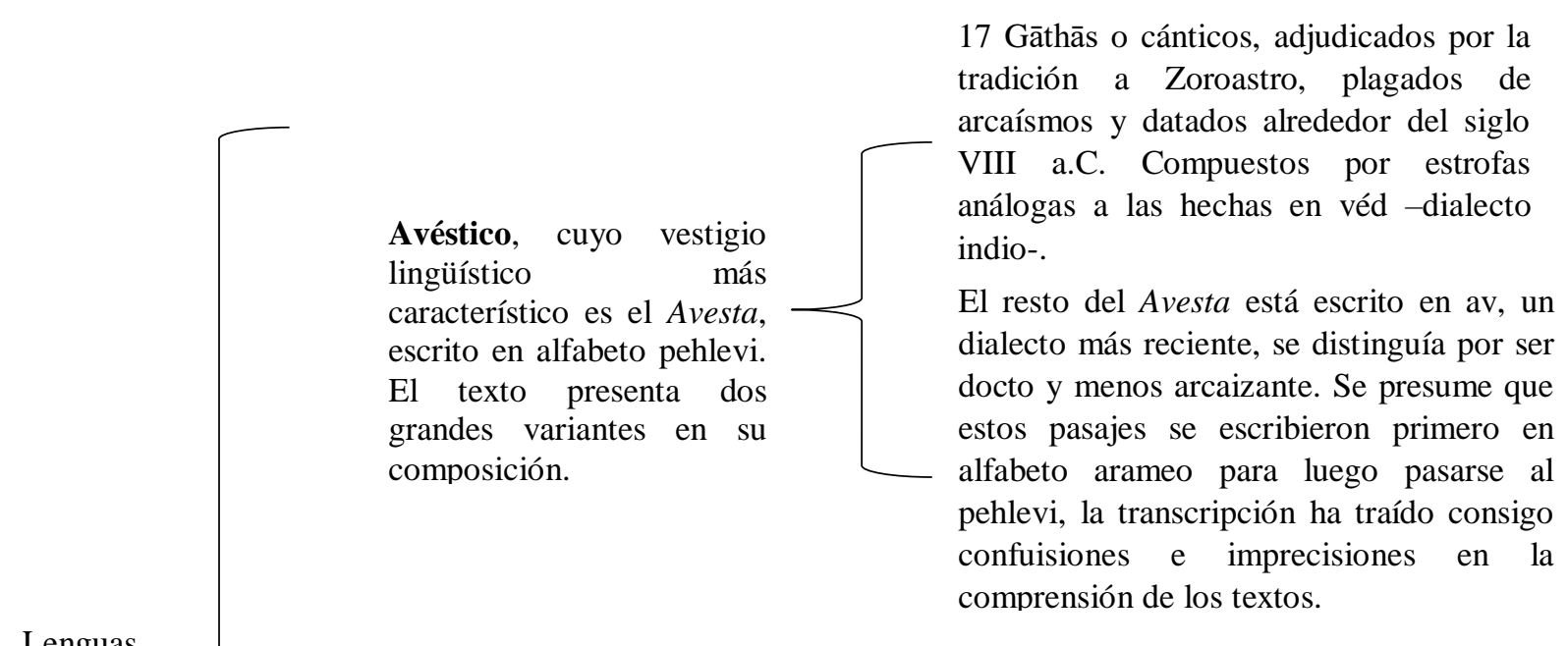

Persa antiguo, inscripciones de la época imperial (Dario I y Jerjes ss. VI-V a.C.). La lengua cayó en desuso al declinar el poder de los aqueménidas.

Medo y escita, no se han conservado textos escritos en estas lenguas, se sabe de ellas por referencias de autores griegos.

Para mayor información al respecto cf. Adrados, Bernabé, Mendoza (1995: pp. 108-110)

\section{BIBLIOGRAFÍA}

ADRADOS, Francisco; BERNABÉ, Alberto; MENDOZA, Julia. Manual de lingüística indoeuropea, Tomo I. 1 ed. Madrid: Ediciones Clásicas, 1995, 402 pp. ALTÄGYPTISCHE DICHTUNG. Traducción de Erik Hornung. 1 ed. Stuttgart, Reclam, 2006, 189 pp.

ALTÄGYPTISCHE ZAUBERSPRÜCHE. Traducción de Hans Fischer Elfert. 1 ed. Stuttgart, Reclam Verlag, 2005, 187 pp.

ÁLVAREZ-PEDROSA NÚÑEZ, Juan Antonio. “Muerte, tránsito del alma y juicio particular en el zoroastrismo en comparación con textos órficos." En 
BERNABÉ, Alberto; CASADESÚS, Francesc (coordinadores). Orfeo y la tradición órfica: II Un reencuentro. Madrid. Akal, 2008, pp. 991-1013.

THE EGYPTIAN BOOK OF THE DEAD. Edición interlineal egipcio-inglés, traducción de Wallis Budge. 3 ed. Nueva York, 2006, 377 pp.

THE ANCIENT EGYPTIAN BOOK OF THE DEAD. Traducción de Raymond O. Faulkner. 1 ed. Nueva York, 2005, 223 pp.

THE ANCIENT EGYPTIAN PYRAMID TEXTS. Traducción de James P. Allen. 2 ed.. Atlanta: Society of Biblical Literature, 2015, 381 pp.

ANTIKE ZAUBERSPRÜCHE. Traducción de Alf Önnerfors. 1 ed. Stuttgart: Reclam Verlag, 1991, 72 pp.

APULEYO. Apología o discurso sobre la magia en defensa propia. Edición bilingüe latín-castellano, traducción de Roberto Heredia Correa. 1 ed. México: UNAM, 2003, 135 pp.

ARISTÓTELES. Fragmentos. Traducción de Álvaro Vallejo Campos. 1 ed. Madrid: Gredos, 2005, 499 pp.

ASANTE, Kete Asante. The Egyptian Philosophers: Ancient African voices from Imhotep to Akhenaten.1 ed. Chicago: African-American Images, 2000, 126 pp.

BETRÒ, Carmela. Heilige Zeichen. Traducción de Christiane von Bechtolsheim. Köln: Marixverlag, 2004, 251 pp.

BREMMER Jan. "The birth of the term 'Magic'". Zeitschrift für Papyrologie und Epigraphik. Bonn, Rudolf Habelt GmbH, Band 126, 1999, pp. 1-12.

BUDGE, Wallis. Egyotian Magic. 1 ed. Londres: Arkana, 1988, 234 pp.

BURKERT, Walter: De Homero a los magos: La tradición oriental en la cultura griega. Traducción de Xavier Riu. 1 ed. Barcelona: El Acantilado, 2002, 172 pp.

CALVO MARTÍNEZ, José Luis. “¿Magos griegos o persas? Los usos más antiguos del término magos: Heráclito, Sófocles, Eurípides y el Papiro Derveni". MHNH, Revista Internacional sobre Magia y Astrología Antiguas. Malaga: Editorial Canales Siete, Vol. 7, 2007, pp. 301-314.

CONFUCIO: Analectas. Traducción de Alonso Colodrón. Madrid: EDAF, 1998. 
CHEN Yong, ¿Es el confucianismo una religión?: La controversia sobre la religiosidad confuciana, su significado y trascendencia. México: El Colegio de México, 2012.

THE EDWIN SMITH SURGICAL PAPYRUS: TRANSLATION AND COMMENTARY, VOL. 1. Traductor James Henry Breasted. 1 ed. Chicago: The University of Chicago Oriental Institute Publications, 1930, $596 \mathrm{pp}$.

THE EGYPTIAN BOOK OF THE DEAD: (PAPYRUS OF ANI). Traducción y transliteración de Wallis Budge. Edición bilingüe egipcio jeroglífico-inglés. Nueva York: Dover Books, 377 pp.

FELDMAN, Louis. "Homer and the Near East: The Rise of the Greek Genius". The Biblical Archeologist, Vol. 59, No. 1 (Mar. 1996). The Oriental Schools of Oriental Research, 1996, pp. 13-21.

FILÓN. Todo hombre bueno es libre. Traducción de Francisco de P. Samaranch. 2 ed. Buenos Aires: Aguilar, 1977, 86 pp.

FISCHER-ELFERT, Hans. "Two Oracle Petitions adressed to Horus-Khau with some notes on the oracular amuletic drecrees". The Journal of Egyptian Archaeology, Vol. 82. Egyptian Exploration Society, 1996. Pp. 129-144.

GARCÍA NOVO, Elsa. "Las dos caras del protagonist en Los Persas de Esquilo". Cuadernos de Filología Clásica, Estudios Griegos e Indeuropeos, No. 15, 2005. UCM, pp. 49-62.

DIE GOLDENEN WEISHEITEN VON ZARATHUSTRA. Traducción y compilación de Aria Homayoun. Edición bilingüe farsí-alemán. Berlín: Gardoon Verlag, 2012, 156 pp.

HERÓDOTO, Historia: Libros I y II. Traducción de Carlos Schrader. Madrid. Gredos, 2000.

HERÓDOTO, Historia: Libros III y IV. Traducción de Carlos Schrader. Madrid. Gredos, 2000.

HORNUNG, Erik. Introducción a la egiptología: Estado, métodos, tareas. 1 ed. Traducción de Francesc Ballesteros. Madrid, Trotta, 169 pp.

IBN JALDÚN, Introducción a la historia universal. Traducción de Elías Trabulse. México. FCE, 2011.1164 pp.

JACOBY, Felix. Die Fragmente der griechischen Historiker: Continued. Part four, Biography and Antiquarian Literature. Edición de Guido Schepens. Leiden: Brill, 1998, 392 pp. 
JAMES, George, Stolen legacy. Estados Unidos. African American Images, 2001. 191 pp.

JOHNSON Sarah; GAGER John; HIMMELFARB Martha; MEYER Martin; SCHMIDT Brian; FRANKFURTER David; Graf Fritz. "Magic in the Ancient World". Numen. Leiden. Vol. 46, No. 3, 1999, pp. 291-325.

KINGSLEY, Peter: Filosofía Antigua, misterios y magia: Empédocles y la tradición pitagórica. Traducción de Alejandro Coroleu. 1 ed. Girona: Atalanta, 2008. $564 \mathrm{pp}$.

LÜTH Paul. Die japanische Philosophie. Tübingen: J.C.B. Mohr, 1944.

LIBRO DE LOS MUERTOS. Traducción de Federico Lara Peinado. 2 ed. Madrid: Tecnos, 1993. 401pp.

EL LIBRO DE LOS MUERTOS DE LOS ANTIGUOS EGIPCIOS. 1 ed. Traducción de Paul Braguet. Traducción al castellano de Ramón Alfonso Díez Aragón y Ma. Del Carmen Blanco Moreno. Bilbao. Desclee, 2000, 308 pp.

MARTÍN HERNÁNDEZ, Raquel. "Literatura mágica y pseudocientífica atribuida a Orfeo". En BERNABÉ, Alberto; CASADESÚS, Francesc (coordinadores). Orfeo y la tradición órfica: I Un reencuentro. Madrid. Akal, 2008, pp. 437-458.

BERNABÉ, Alberto; CASADESÚS, Francesc (coordinadores). Orfeo y la tradición órfica: I Un reencuentro. Madrid. Akal, 2008, pp. 801-814.

MOMIGLIANO, Arnaldo. La sabiduría bárbara: los límites de la helenización. Traducción de Gabriela Ordiales. 2 ed. México, FCE, 1999, 280 pp.

MUÑOZ DELGADO, Luis. Léxico de magia y religión en los papiros mágicos griegos. 1 ed. Madrid: CSIC, 2001, 183 pp.

ONFRAY Michel. Las sabidurías de la antigüedad: Contrahistoria de la filosofia, I. Traducción de Marco Aurelio Galmarini. 1 ed. Barcelona: Anagrama., 2013, $330 \mathrm{pp}$.

ORÁCULOS CALDEOS/ NUMENIO DE APAMEA: FRAGMENTOS Y TESTIMONIOS. Traducción de Francisco García Bazán. 1 ed. Madrid: Gredos, 1991. 312 pp.

SUDA ON LINE: http://www.stoa.org/sol-bin/search.pl 
RITNER K. Robert. "Magic". The Oxford Encyclopedia of Ancient Egypt. New York, 2001. Pp. 321-336.

SPENCE, Lewis: Ancient Egypt: Myhts and legends. 1 ed. Nueva York: Dover, 1990, 369 pp.

Wieleitner Heinrich: "War die Wissenschaft der alten Ägypter wirklich nur praktisch?" Isis, The University of Chicago Press. No. 1, Vol 9, pp. 11-28. 